\title{
Dendritic cell-activated cytokine-induced killer cell-mediated immunotherapy is safe and effective for cancer patients $>65$ years old
}

\author{
YANFENG LIU ${ }^{1,2^{*}}$, HAIBO LIU ${ }^{1,3^{*}}$, HAUSHENG LIU ${ }^{1,3}$, PENGCHENG HE ${ }^{1,3}, \mathrm{JING} \mathrm{LI}^{1,3}, \mathrm{XIN} \mathrm{LIU}^{1,3}$, \\ LIMEI CHEN $^{1,3}$, MENGCHANG WANG ${ }^{1,3}$, JIEJING XI ${ }^{1,3}$, HUAIYU WANG $^{1,3}$, HAITAO ZHANG ${ }^{1,3}$, \\ YING ZHU ${ }^{3}$, WEI ZHU ${ }^{3}$, JING NING $^{3}$, CAILI GUO $^{3}$, CHUNHONG SUN $^{3}$ and MEI ZHANG ${ }^{1,3}$ \\ ${ }^{1}$ Department of Hematology, The First Affiliated Hospital, Xi'an Jiaotong University, Xi'an, Shaanxi 710061; \\ ${ }^{2}$ Department of Hematology, Xiangya Hospital, Central South University, Changsha, Hunan 410008; ${ }^{3}$ Biological \\ Immune Therapy Center, The First Affiliated Hospital, Xi'an Jiaotong University, Xi'an, Shaanxi 710061, P.R. China
}

Received June 29, 2015; Accepted August 25, 2016

DOI: $10.3892 / 01.2016 .5337$

\begin{abstract}
Individuals $>65$ years old account for a large proportion of cancer patients, and usually have poor prognoses due to relative weaker physiological function and lower drug tolerance. To characterize the efficacy and safety of dendritic cell (DC)-activated cytokine-induced killer cell (CIK)-mediated treatment, and develop an adoptive immunotherapy for cancer patients $>65$ years old, a retrospective study was performed in 58 cancer sufferers who received 1-4 cycles of DC-activated CIK (DC-CIK) treatment and evaluated the response (tumor remission rate) and toxicity (side effects to the treatment). The present results showed that DCs and CIKs could be expanded rapidly in vitro, and following co-culture with $\mathrm{DCs}$, the population of cluster of differentiation (CD) $3^{+}, \mathrm{CD}^{+} \mathrm{CD}^{+}$, $\mathrm{CD}^{+}{ }^{+} \mathrm{CD} 8^{+}$and $\mathrm{CD}^{+}{ }^{+} \mathrm{CD} 56^{+} \mathrm{CIK}$ s was significantly increased compared to CIKs without DC activation $(\mathrm{P}=0.044)$. In addition, DC-CIK infusion produced marked clinical outcomes, resulting in an objective remission rate, overall clinical benefit rate and Karnofsky performance status of 44.83, 75.86 and $87.28 \pm 5.46 \%$, respectively, which was significantly improved compared with prior to treatment $(\mathrm{P}<0.05)$. Additionally, subsequent to two cycles of this immunotherapy, several tumor marker expression levels declined, returning to the normal range. The proportion of $\mathrm{CD}^{+} \mathrm{CD}^{+}(\mathrm{P}=0.017)$ and $\mathrm{CD}^{+} \mathrm{CD}^{+}$ $(\mathrm{P}=0.023)$ lymphocytes, and the population of $\mathrm{CD} 4 / \mathrm{CD} 8$ cells
\end{abstract}

Correspondence to: Professor Mei Zhang, Department of Hematology, The First Affiliated Hospital, Xi'an Jiaotong University, 277 Yanta West Road, Xi'an, Shaanxi 710061, P.R. China

E-mail: zhangmei_xjtu@hotmail.com

*Contributed equally

Key words: dendritic cells, cytokine-induced killer cells, immunotherapy, cancer
$(\mathrm{P}=0.024)$ were also increased. In conclusion, the present study suggests that the immunotherapy mediated by DC-CIK is safe and effective for cancer patients aged $>65$ years.

\section{Introduction}

In European countries, almost 1,000,000 cases of cancer are diagnosed each year, and among them, $>55 \%$ of cancers occur in people who are aged $>65$ years (1). It is estimated that $>60 \%$ of patients with malignancies will be in this age group by the year 2020, if the present demographic trends continue (2). Additionally, there are numerous inadequacies in the treatment and care of older people ( $>65$ years) with cancer compared to younger ( $\leq 50$ years) patients, as older cancer patients are usually diagnosed later in the disease process, and in consideration of their physiological function, only less aggressive treatment may be administered during the therapeutic process, which leads to the comparatively lower survival rates $(3,4)$. Therefore, to choose a safe, effective, and tolerable treatment for cancer patients aged $>65$ years is an important and urgent challenge for clinicians.

Dendritic cells (DCs) are major antigen-presenting cells. They are capable of capturing and processing tumor antigens, expressing lymphocyte co-stimulatory molecules, and secreting cytokines to initiate immune responses (5). Cytokine-induced killer cells (CIKs) are a heterogeneous population of effector CD8 T cells with diverse $\mathrm{T}$ cell receptor specificities, possessing non-major histocompatibility complex (MHC)-restricted cytolytic activities against tumor cells (6). Therefore, CIKs can lyse tumor cells in a non-MHC-restricted manner and serve as an alternative cellular immunotherapy (7). Immunotherapy has become the fourth major treatment option for malignant tumors, following surgery, chemotherapy and radiotherapy (8). A number of adoptive immunotherapies mediated by various killer cells have been reported, including tumor-infiltrating lymphocytes (TIL) (9), lymphokine-activated killer cells (LAK) (10), and anti-CD3 monoclonal antibody-induced killer cells (11). However, the therapeutic efficacy is not as good as expected; it is hypothesized that 
this maybe associated with the low anti-tumor activities of the immunocyte (12). At present, CIKs have been recognized as a new type of anti-tumor effector cell, which are predominantly $\mathrm{CD}^{+}{ }^{+} \mathrm{CD} 56^{+}$type II natural killer T-cells, and can be expanded from peripheral blood mononuclear cells (PBMCs) and proliferate rapidly with the timed addition of cytokines, such as interleukin-2 (IL-2), interferon- $\gamma($ IFN- $\gamma$ ) and anti-CD3 monoclonal antibody (mAb) in vitro (13). CIKs have stronger anti-tumor activity and broader spectrum of tumor targets than other reported anti-tumor effector cells (8). In addition, CIKs can regulate and generally enhance the immune functions in patients with several types of cancer (7). In previous years, a large number of studies $(5,14,15)$ have shown that DCs could activate CIKs by co-culture on changing the surface molecule expression, increasing cytokine secretion and causing a higher cytolytic capacity (16). The present retrospective study was performed to evaluate the effects and safety of DC-CIK treatment on different types of cancers in patients aged $>65$ years.

\section{Patients and methods}

Patient selection. Between September 2014 and January 2015, 58 patients with cancer, including solid tumors and hematological malignancies, were treated using immunotherapy (Table I). Criteria for inclusion in the present study were: Histopathologically confirmed cancers; expected survival duration $>3$ months; Karnofsky performance status (KPS) $>40 \%$; aged $>65$ years; free of congestive heart failure, severe coronary artery disease, cardiac arrhythmias, organ transplant, serious infection, severe autoimmune disease or central nervous system disease; and without chemotherapy or immunomodulatory treatment during the previous 4 weeks. Informed consent was obtained from all patients prior to therapy.

DCs and CIKs preparation. The DCs and CIKs were generated following Good Manufacturing Practice guidelines (17). Recombinant human granulocyte-macrophage colony-stimulating factor (rhGM-CSF; Peprotech, London, UK) was injected $(150 \mu \mathrm{g}) 24 \mathrm{~h}$ prior to blood collection to mobilize white blood cells. PBMCs were collected from patients or healthy donors using a COBE Spectra continuous flow blood cell separator (Caridian BCT, Lakewood, CO, USA). The concentrated PBMCs were suspended immediately in CIK medium [X-VIVO 20 serum-free medium (Lonza, Cologne, Germany), $50 \mathrm{ng} / \mathrm{ml}$ anti-CD3 antibody (BD Biosciences, San Jose, CA, USA), 1,000 U/ml recombinant human IL-2 (rhIL-2; Peprotech) and 1,000 U/ml recombinant human IFN- $\gamma$ (Peprotech)], at $37^{\circ} \mathrm{C}$ with $5 \% \mathrm{CO}_{2}$ and fed every 5 days in fresh complete medium with various types of cytokines, as aforementioned.

For DC culture, PBMCs were cultured in X-VIVO 20 medium containing $1,000 \mathrm{U} / \mathrm{ml} \mathrm{IL-4}$ and $500 \mathrm{U} / \mathrm{ml}$ rhGM-CSF. Autologous tumor lysate $(100 \mu \mathrm{g} / \mathrm{ml})$ was added at day 6 and co-cultured with DCs for $24 \mathrm{~h}$. For CIK activation, CIKs were co-cultured with DCs loaded with tumor antigen for 7 days. The DC-CIK cells were harvested and analyzed for phenotype, then suspended in $100 \mathrm{ml}$ saline for intravenous injection. The final cell products were assessed for viability by the dye-exclusion test and checked twice for possible contamination by bacteria, fungi and endotoxins.

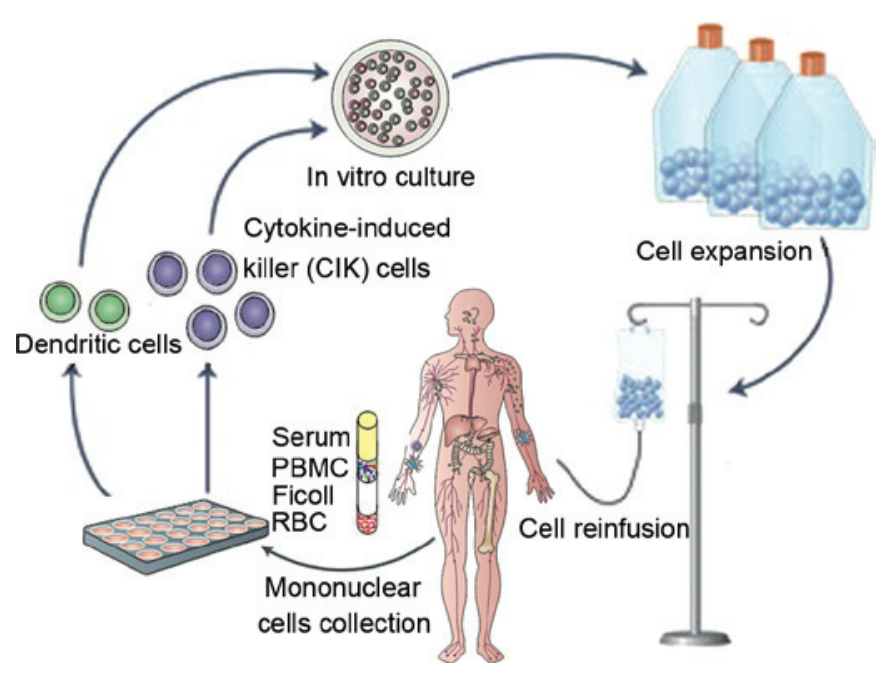

Figure 1. Procedure for DC-CIK cells preparation and infusion. DC, dendritic cell; CIK, cytokine-induced killer cells; RBC, red blood cell; PBMC, peripheral blood mononuclear cell.

CIKs phenotype detection. Approximately $5 \times 10^{5}$ CIKs, with or without activation by DCs, were resuspended in $20 \mu 12 \%$ fetal bovine serum and $1 \%$ sodium azide in phosphate buffered saline (PBS) and incubated with $10 \mu \mathrm{l}$ antibody against CD3-fluorescein isothiocyanate (FITC; clone, UCHT1; dilution, 1:2.5; catalog no., 11-0038-80; eBioscience, San Diego, CA, USA), CD4/FITC and CD8-RPE (clones, MT310 and DK25; dilution, 1:50; catalog no., FR86850), and CD3-FITC/ CD56-RPE (clones, UCHT1 and C5.9; dilution, 1:50; catalog no., FR91250; Dako, Carpentaria, CA, USA) for $30 \mathrm{~min}$ at $4^{\circ} \mathrm{C}$. Following incubation, cells were washed twice with PBS and resuspended in $1 \mathrm{ml}$ staining buffer (BD Pharmingen, San Diego, CA, USA). The cell population was analyzed using flow cytometry (FCM; BD Biosciences).

Treatments. Patients received 1-4 cycles of DC-activated CIK treatment at intervals of 1 month after chemotherapy/radiotherapy. For each cycle, patients were treated with a median of $(8.3 \pm 0.61) \times 10^{9}$ DC-activated CIKs (range, 8.0-12.6x10 ${ }^{9}$ ) at 1-day intervals for two intravenous infusions (Fig. 1). Additional care was provided whenever required. Clinical examinations of these patients were performed by oncology specialists weekly or biweekly, including a complete blood count, liver and renal function tests, computed tomography (CT) or magnetic resonance imaging (MRI) scan.

Efficacy evaluation. Efficacy evaluation was performed prior to and subsequent to 2 cycles of DC-CIK treatment. The evaluation indexes of therapeutic efficiency included the objective remission rate of measurable focus region, which was performed according to the World Health Organization criterion, and comparing the tumor size prior to and subsequent to 2 cycles of treatment by CT/MRI. The curative effect was further divided into complete remission (CR), partial remission (PR), stable disease (SD) and progressive disease (PD). The ratio of $\mathrm{CR}$ and $\mathrm{PR}$ was analyzed. The clinical benefit rate (CBR) was also analyzed. The quality of life and physical improvement were measured by KPS, and the assessment of pain grade was evaluated by numeric rating 
Table I. Demographic and clinical characteristics of enrolled patients.

Demographic and clinical characteristics Number of patients

\begin{tabular}{|c|c|}
\hline \multicolumn{2}{|l|}{ Age, years } \\
\hline Range & $65-84$ \\
\hline Median & 72.7 \\
\hline \multicolumn{2}{|l|}{ Gender } \\
\hline Male & 49 \\
\hline Female & 9 \\
\hline \multicolumn{2}{|l|}{ Tumor types } \\
\hline Gallbladder carcinoma & 4 \\
\hline Colorectal adenoma & 18 \\
\hline Lung cancer & 6 \\
\hline Leukemia & 2 \\
\hline Gastric carcinoma & 14 \\
\hline Esophagus cancer & 7 \\
\hline Pelvic cancer & 3 \\
\hline Multiple myeloma & 1 \\
\hline Liver cancer & 3 \\
\hline \multicolumn{2}{|l|}{ Stage } \\
\hline II & 19 \\
\hline III-IV & 39 \\
\hline \multicolumn{2}{|l|}{ Prior therapy } \\
\hline Surgery & 14 \\
\hline Radiotherapy & 26 \\
\hline Chemotherapy & 48 \\
\hline \multicolumn{2}{|l|}{ KPS } \\
\hline $40-60$ & 11 \\
\hline $60-80$ & 40 \\
\hline$>80$ & 7 \\
\hline
\end{tabular}

KPS, Karnofsky performance status.

scale (NRS). The tumor markers carcinoembryonic antigen (CEA), $\alpha$ fetoprotein (AFP), carbohydrate antigen-125 (CA125), carbohydrate antigen-199 (CA199), carbohydrate antigen-724 (CA724), prostate special antigen (PSA) and neuron-specific enolase (NSE) were also detected by Immunofluorescence Analysis system (Zeiss AG, Thornwood, NY, USA). The lymphocyte subpopulation, consisting of the $\mathrm{CD}^{+}, \mathrm{CD}^{+} \mathrm{CD}^{+}$and $\mathrm{CD} 3^{+} \mathrm{CD}^{+}$populations of $\mathrm{T}$ lymphocytes, was measured by FCM, and the ratio of CD4:CD8 cells was also analyzed.

Statistical analysis. The measurement data was compared using Student's $t$-test and analyzed by SPSS 17.0 software (SPSS, Inc., Chicago, IL, USA). P $<0.05$ was considered to indicate a statistically significant difference.

\section{Results}

Amplification of DC-CIK in vitro. The median count of untreated PBMCs of all patients was $3.16 \times 10^{9}$ (range,
Table II. Distribution of toxicity.

\begin{tabular}{llc}
\hline Side effects (WHO criteria) & $\begin{array}{c}\text { Grade I-II, } \\
\mathrm{n}(\%)\end{array}$ & $\begin{array}{c}\text { Grade } \\
\text { III-IV, } \mathrm{n}\end{array}$ \\
\hline Chills & $4(6.90)$ & 0 \\
Fever & $7(12.07)$ & 0 \\
Hematological symptoms & $5(8.62)$ & 0 \\
Anemia & $2(3.45)$ & 0 \\
Leucopenia & $2(3.45)$ & 0 \\
Thrombocytopenia & $1(1.72)$ & 0 \\
Gastrointestinal symptom & $3(5.17)$ & 0 \\
Nausea and vomiting & $2(3.45)$ & 0 \\
Diarrhea & $1(1.72)$ & 0 \\
Respiratory symptom (dyspnea) & $1(1.72)$ & 0 \\
Skin symptom (allergy) & $3(5.17)$ & 0 \\
Circulatory system (arrhythmias) & $2(3.45)$ & 0 \\
Neurological symptoms & $8(13.79)$ & 0 \\
Fatigue and headaches & $6(10.34)$ & 0 \\
Paresthesia & $2(3.45)$ & 0 \\
\hline
\end{tabular}

WHO, World Health Organization.

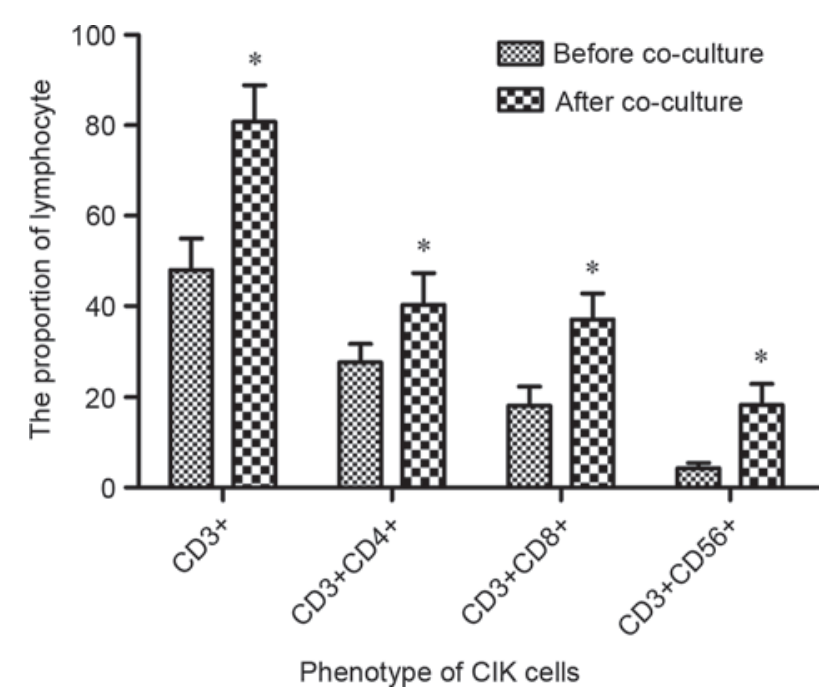

Figure 2. Phenotype of CIK cells. The population of $\mathrm{CD}^{+}, \mathrm{CD}^{+} \mathrm{CD}^{+}$, $\mathrm{CD}^{+}{ }^{+} \mathrm{CD} 8^{+}$and $\mathrm{CD}^{+}{ }^{+} \mathrm{CD} 56^{+} \mathrm{CIK}$ s were significantly increased by DCs activation compared with CIKs without $\mathrm{DC}$ activation. ${ }^{\mathrm{P}} \mathrm{P}<0.05$. $\mathrm{CD}$, cluster of differentiation; CIK, cytokine-induced killer cell; DC, dendritic cell.

$2.67 \times 10^{9}-3.59 \times 10^{9}$ ) per cycle. The median count of CIK cells after 14 days of amplification could reach $9.64 \times 10^{9}$ (range, $8.57 \times 10^{9}-12.41 \times 10^{9}$ ) per cycle. On the basis of trypan blue staining, the cellular vitality was $>95 \%$.

Phenotype detection of DC-activated CIKs. To determine the immunological activation of DCs on CIKs, the phenotype of CIKs prior to and subsequent to induction by DCs was analyzed using FCM. Fig. 2 demonstrated that the population of $\mathrm{CD}^{+}, \mathrm{CD}^{+} \mathrm{CD}^{+}, \mathrm{CD}^{+} \mathrm{CD}^{+}$and $\mathrm{CD}^{+} \mathrm{CD}^{+} 6^{+} \mathrm{CIK}$ cells were significantly increased between $47.94 \pm 7.02,27.56 \pm 4.05$, $18.13 \pm 4.26$ and $4.28 \pm 1.18$ (prior to co-culture) to $80.78 \pm 8.11$, 
A

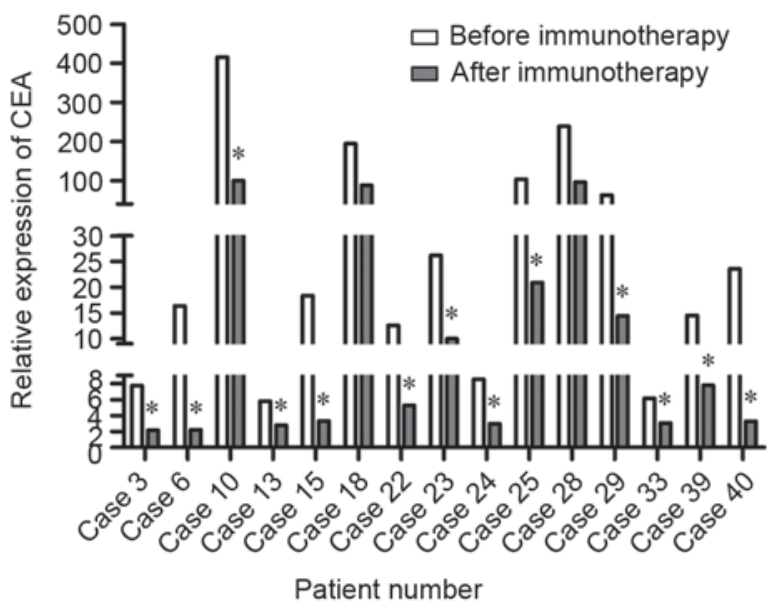

C

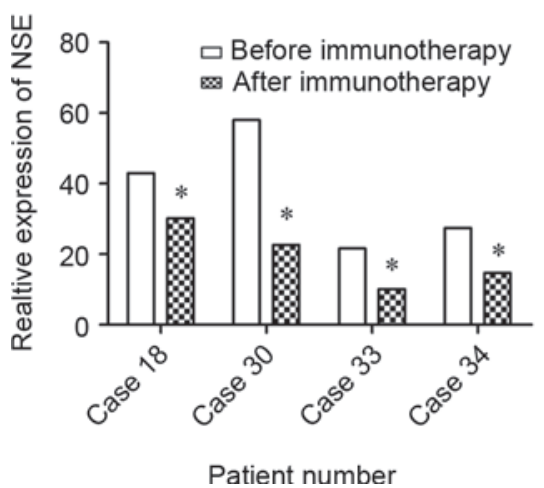

D

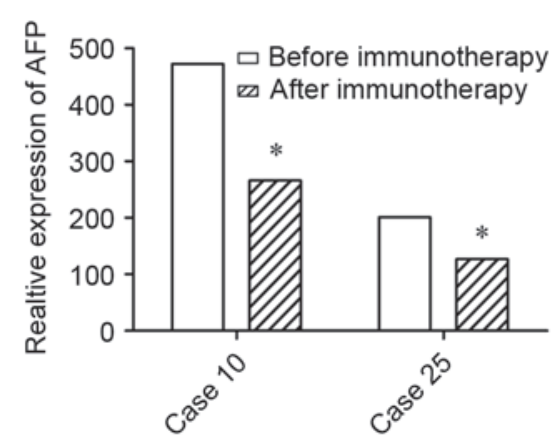

Patient number

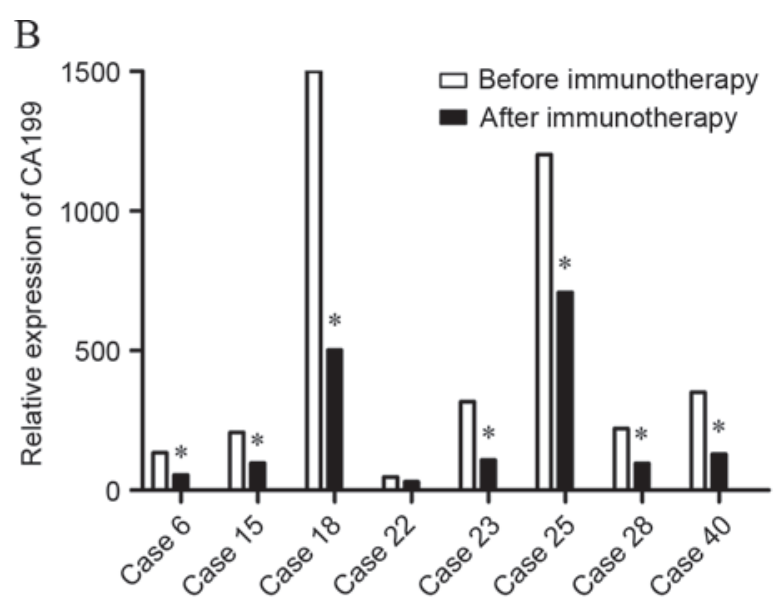

Patient number
$\mathrm{E}$

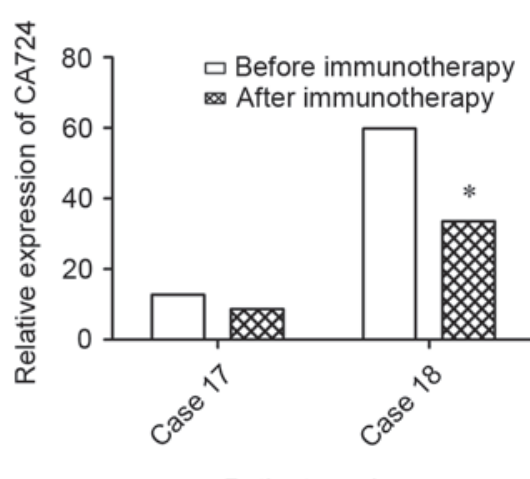

Figure 3. Tumor marker level of patients. The levels of tumor markers were monitored prior to and subsequent to 2 cycles of DC-CIK immunotherapy using FCM. (A) The expression of CEA in 15 cases. Expression in 13 patients decreased significantly compared with prior to DC-CIK infusion, and the expression in 7 patients reached the normal range. (B) The expression of CA199 in 8 patients. Expression in 7 patients decreased significantly compared with prior to DC-CIK infusion, and the expression in 1 patient reached the normal range. (C) The expression of NSE in 4 cases. The expression of all 4 patients decreased compared with prior to DC-CIK infusion, and 2 patients demonstrated a decrease to the normal range. (D) The expression of AFP in 2 cases. AFP expression in the 2 patients decreased compared with prior to DC-CIK infusion. (E) The expression of CA-724 in 2 cases. The expression of CA-724 decreased significantly in the 2 patients compared with prior to DC-CIK infusion, and the level in 1 patient reached the normal range. ${ }^{*} \mathrm{P}<0.05$. DC, dendritic cell; CIK, cytokine-induced killer cell; FCM, flow cytometry; CEA, carcinoembryonic antigen; NSE, neuron-specific enolase; AFP, $\alpha$ fetoprotein; CA, cancer antigen 724.

$40.31 \pm 6.94,37.02 \pm 5.78$ and $18.33 \pm 4.60 \%$ subsequent to co-culture, respectively $(\mathrm{P}=0.044)$.

Treatment response. In total, 26 out of 58 patients had a measurable focus region: 1 achieved CR and 25 achieved PR, with an objective remission rate of $44.83 \%$. Among the remaining patients, 30 achieved SD (51.72\%) and 2 demonstrated PD $(3.45 \%)$. There were 42 of 58 patients who underwent CBR evaluation: 36 had both KPS that was increased $>20 \%$ and pain relief of $>50 \%$, with an overall CBR of $85.71 \%(36 / 42)$. Additionally, following treatment with DC-activated CIKs, the KPS was $87.28 \pm 5.46$, which was significantly higher than prior to treatment $(69.02 \pm 7.45)$. Subsequently, the level of tumor markers including CEA, AFP, CA125, CA199, CA724, PSA and NSE was monitored. The results demonstrated that there were 15, 8, 4, 2 and 2 patients with high CEA, CA199, NSE, CA724 and AFP expression, respectively. Subsequent to DC-CIK mediated immunotherapy for 2 cycles, 9 patients attained almost normal tumor marker expression levels. The remaining patients did not demonstrate a decline to the normal range, but CEA expression decreased (Fig. 3). Referring to the lymphocyte subpopulation, the present test results indicated that $75 \%$ of patients showed an increase in $\mathrm{CD} 3{ }^{+} \mathrm{CD} 4^{+}$lymphocytes $(\mathrm{P}=0.017)$ and $50 \%$ of patients showed an increase in $\mathrm{CD}^{+} \mathrm{CD}^{+}$lymphocytes $(\mathrm{P}=0.023)$. The population of CD4/CD8 cells was significantly increased as well $(\mathrm{P}=0.024)$ (Fig. 4).

Treatment toxicity. The distributions of side effects in the patients are shown in Table II. No serious side effects that may present a safety hazard to life were observed. No patient failed to complete the DC-CIK immunotherapy. There were no grade III-IV cell-associated toxicities, and common grade I-II toxicities consisted of transient chills, fever, fatigue, headache and anemia.

\section{Discussion}

Although systemic chemotherapy, radiotherapy and surgery are the principle treatments for cancers, the prognosis remains poor, particularly in older cancer patients, due to their poor tolerance and weaker immunity (18). Increasing 
A

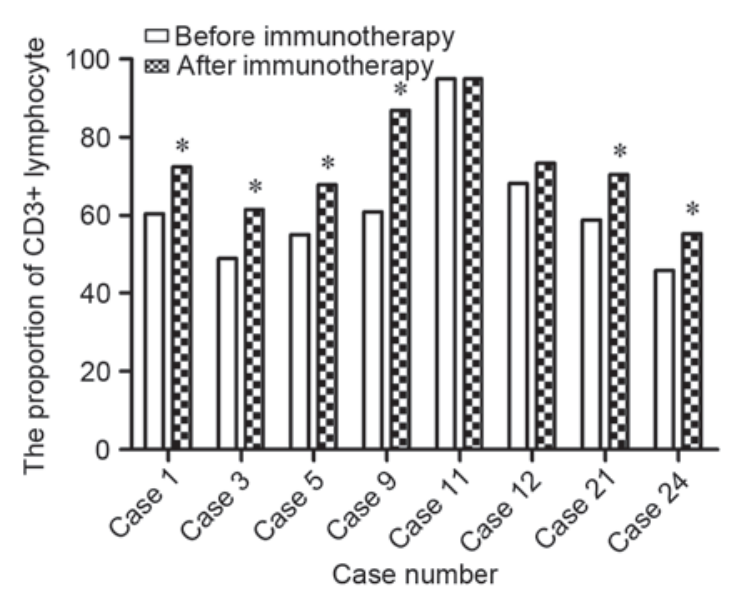

C

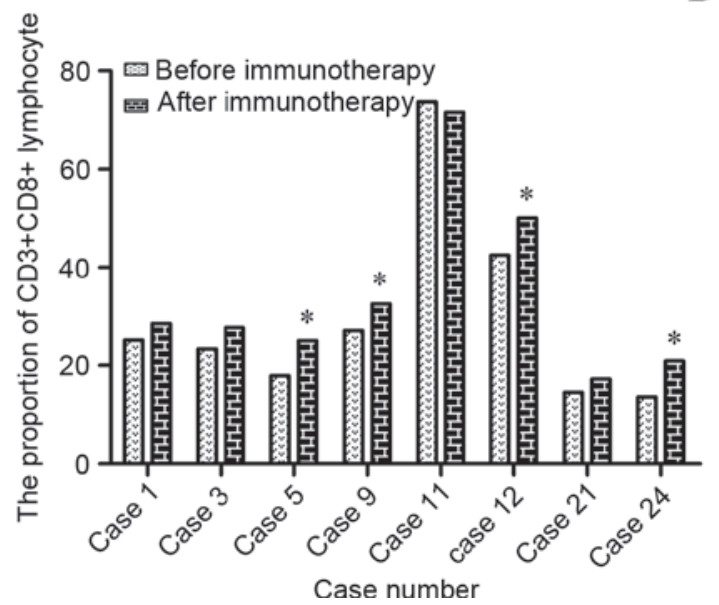

D
B
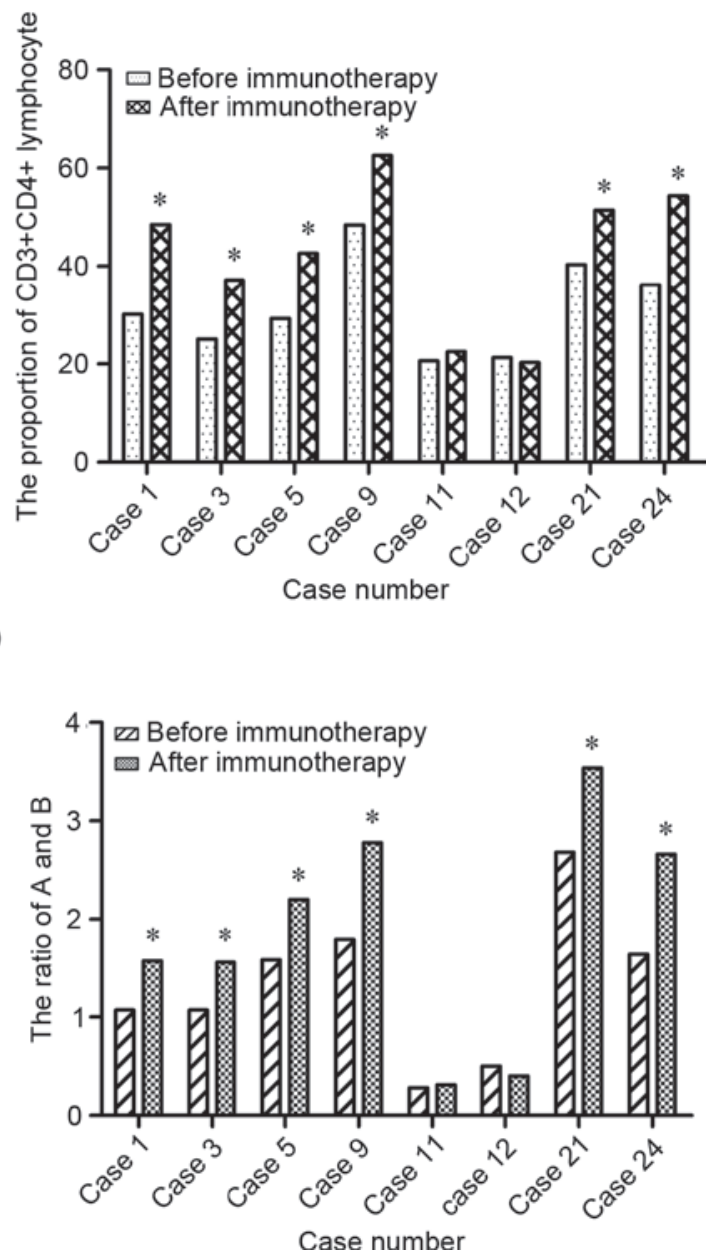

Figure 4. Lymphocyte subpopulation of patients. The lymphocyte subpopulation was detected prior to and subsequent to 2 cycles of DC-CIK immunotherapy in 8 patients. (A) The proportion of CD3 ${ }^{+}$lymphocytes. In total, 6 patients showed $\mathrm{CD} 3^{+}$lymphocyte increase following DC-CK treatment. (B) The proportion of $\mathrm{CD}^{+} \mathrm{CD}^{+}$lymphocytes was analyzed in 8 cases, and 6 patients showed $\mathrm{CD} 3^{+} \mathrm{CD} 4^{+}$lymphocyte increase following DC-CK treatment. (C) The proportion of $\mathrm{CD}^{+} \mathrm{CD}^{+}$lymphocytes. In total, 4 patients showed CD3 ${ }^{+} \mathrm{CD} 8^{+}$lymphocyte increase following DC-CIK treatment. (D) The ratio of CD4 and CD8 lymphocytes. Overall, 6 patients showed increased levels. " $\mathrm{P}<0.05$. DC, dendritic cell; CIK, cytokine-induced killer cell; $\mathrm{CD}$, cluster of differentiation.

clinical studies have suggested that immunotherapy may serve as an excellent strategy to improve efficiency of cancer therapy (19). Adoptive immunotherapy using CIKs has shown significant anti-tumor activity in pre-clinical experiments and various animal tumor models (20). In a previous retrospective study, our results showed that DCs could potentially increase the population of the hallmark effector $\mathrm{CD} 3{ }^{+} \mathrm{CD} 56^{+}$ cells, which have powerful immune cytotoxicity effects (21). In the present study, DC-CIK immunotherapy was performed subsequent to different prior therapy in 58 patients; it was well tolerated, and could prevent tumor progression to a certain extent and improve quality of life for patients. As tumor markers may reflect tumorigenesis, progression and response to treatment, determining the levels of markers prior to and subsequent to immunotherapy in those patients may provide information regarding the curative effect of DC-activated CIKs action. The current study analyzed the expression changes of several tumor markers, such as CEA, CA199 and NSE. The present monitoring results indicated patients with DC-CIK mediated immunotherapy had a lower level of those indexes compared with prior to DC-CIK infusion.
DCs, known as the most powerful antigen presenting cells, have been under intense investigation as components of anti-tumor vaccines, specifically as a delivery mode for tumor antigens (22). CIKs are a novel population of immune effector cells and can be expanded in vitro in the presence of rhIL-2, starting from PBMCs stimulated by IFN- $\gamma$ and anti-CD3 antibody (23). It is well known that CIKs have become suitable candidates for cell therapy regimens in both solid and hematopoietic tumor treatments due to their easy and rapid production in vitro, stronger anti-tumor activity, broader target tumor spectrum, and relatively lower adverse effect compared to other reported anti-tumor effector cells $(24,25)$. In particular, CIKs can regulate and enhance the immune function in patients with cancer, which is particularly suitable for patients aged $>65$ years old.

In conclusion, the current results provide information regarding the outcome of DC-CIK mediated immunotherapy in cancer patients aged $>65$ years. Additional studies of the expression of relevant cytokines, such as IFN- $\gamma$, interleukin, MIG, MCP, TNF- $\alpha$ and TNF- $\beta$, and long-term survival time observation of a larger sample size are required to further investigate the clinical efficacy of this approach. 


\section{Acknowledgements}

This study is supported by a research grant from Shaanxi Province Science and Technology Development Fund (grant no. 2011KTCL03-10).

\section{References}

1. Chouliara Z, Kearney N, Stott D, Molassiotis A and Miller M: Perceptions of older people with cancer of information, decision making and treatment: A systematic review of selected literature. Ann Oncol 15: 1596-1602, 2004.

2. Soubeyran P, Fonck M, Blanc-Bisson C, Blanc JF, Ceccaldi J, Mertens C, Imbert Y, Cany L, Vogt L, Dauba J, et al: Predictors of early death risk in older patients treated with first-line chemotherapy for cancer. J Clin Oncol 30: 1829-1834, 2012.

3. Kenis C, Bron D, Libert Y, Decoster L, Van Puyvelde K, Scalliet P, Cornette P, Pepersack T, Luce S, Langenaeken C, et al: Relevance of a systematic geriatric screening and assessment in older patients with cancer: Results of a prospective multicentric study. Ann Oncol 24: 1306-1312, 2013.

4. Aaldriks AA, Maartense E, le Cessie S, Giltay EJ, Verlaan HA, van der Geest LG, Kloosterman-Boele WM, Peters-Dijkshoorn MT, Blansjaar BA, van Schaick HW and Nortier JW: Predictive value of geriatric assessment for patients older than 70 years, treated with chemotherapy. Crit Rev Oncol Hematol 79: 205-212, 2011.

5. Zhong R, Han B and Zhong H: A prospective study of the efficacy of a combination of autologous dendritic cells, cytokine-induced killer cells, and chemotherapy in advanced non-small cell lung cancer patients. Tumour Biol 35: 987-994, 2014.

6. Gammaitoni L, Giraudo L, Leuci V, Todorovic M, Mesiano G, Picciotto F, Pisacane A, Zaccagna A, Volpe MG, Gallo S, et al: Effective activity of cytokine-induced killer cells against autologous metastatic melanoma including cells with stemness features. Clin Cancer Res 19: 4347-4358, 2013.

7. Jiang J, Wu C and Lu B: Cytokine-induced killer cells promote antitumor immunity. J Transl Med 11: 83, 2013.

8. Hontscha C, Borck Y,Zhou H, Messmer D and Schmidt-Wolf IG: Clinical trials on CIK cells: First report of the international registry on CIK cells (IRCC). J Cancer Res Clin Oncol 137: 305-310, 2011.

9. Turksma AW, Coupé VM, Shamier MC, Lam KL, de Weger VA, Belien JA, van den Eertwegh AJ, Meijer GA, Meijer CJ, Hooijberg E. Extent and Location of Tumor-Infiltrating Lymphocytes in Microsatellite-Stable Colon Cancer Predict Outcome to Adjuvant Active Specific Immunotherapy. Clin Cancer Res. 22: 346-356, 2016.

10. Saito H, Ando S, Morishita N, Lee KM, Dator D, Dy D, Shigemura K, Adhim Z, Nibu K, Fujisawa M and Shirakawa T: A combined lymphokine-activated killer (LAK) cell immunotherapy and adenovirus-p53 gene therapy for head and neck squamous cell carcinoma. Anticancer Res 34: 3365-3370, 2014.

11. Huang J, Li C, Wang Y, Lv H, Guo Y, Dai H, Wicha MS, Chang AE and Li Q: Cytokine-induced killer (CIK) cells bound with anti-CD3/anti-CD133 bispecific antibodies target CD133(high) cancer stem cells in vitro and in vivo. Clin Immunol 149: 156-168, 2013.
12. Zhang J, Zhu L, Wei J, Liu L, Yin Y, Gu Y and Shu Y: The effects of cytokine-induced killer cells for the treatment of patients with solid tumors: A clinical retrospective study. J Cancer Res Clin Oncol 138: 1057-1062, 2012.

13. Lu XC, Yang B, Yu RL, Chi XH, Tuo S, Tuo CW, Zhu HL, Wang Y, Jiang CG, Fu XB, et al: Clinical study of autologous cytokine-induced killer cells for the treatment of elderly patients with diffuse large B-cell lymphoma. Cell Biochem Biophys 62: 257-265, 2012.

14. Gao D,LiC, Xie X,Zhao P, Wei X, Sun W, Liu HC, Alexandrou AT, Jones J, Zhao R and Li JJ: Autologous tumor lysate-pulsed dendritic cell immunotherapy with cytokine-induced killer cells improves survival in gastric and colorectal cancer patients. PLoS One 9: e93886, 2014

15. Zhao P, Bu X, Wei X, Sun W, Xie X, Li C, Guo Q, Zhu D, Wei X and Gao D: Dendritic cell immunotherapy combined with cytokine-induced killer cells promotes skewing toward Th2 cytokine profile in patients with metastatic non-small cell lung cancer. Int Immunopharmacol 25: 450-456, 2015.

16. Yang L, Ren B, Li H, Yu J, Cao S, Hao X and Ren X: Enhanced antitumor effects of DC-activated CIKs to chemotherapy treatment in a single cohort of advanced non-small-cell lung cancer patients. Cancer Immunol Immunother 62: 65-73, 2013.

17. Castiglia S, Mareschi K, Labanca L, Lucania G, Leone M, Sanavio F, Castello L, Rustichelli D, Signorino E, Gunetti M, et al: Inactivated human platelet lysate with psoralen: A new perspective for mesenchymal stromal cell production in Good Manufacturing Practice conditions. Cytotherapy 16: 750-763, 2014.

18. De Angelis R, Sant M, Coleman MP, Francisci S, Baili P, Pierannunzio D, Trama A, Visser O, Brenner H, Ardanaz E, et al: Cancer survival in Europe 1999-2007 by country and age: Results of EUROCARE-5-a population-based study. Lancet Oncol 15: 23-34, 2014.

19. Couzin-Frankel J: Breakthrough of the year 2013. Cancer immunotherapy. Science 342: 1432-1433, 2013.

20. Li H, Wang C, Yu J, Cao S, Wei F, Zhang W, Han Y and Ren XB: Dendritic cell-activated cytokine-induced killer cells enhance the anti-tumor effect of chemotherapy on non-small cell lung cancer in patients after surgery. Cytotherapy 11: 1076-1083, 2009.

21. Wang X, Yu W, Li H, Yu J, Zhang X, Ren X and Cao S: Can the dual-functional capability of CIK cells be used to improve antitumor effects? Cell Immunol 287: 18-22, 2014.

22. Price JD, Hotta-Iwamura C, Zhao Y, Beauchamp NM and Tarbell KV: DCIR2+ cDC2 DCs and Zbtb32 restore CD4+ $\mathrm{T}$ cell tolerance and inhibit diabetes. Diabetes 64: 3521-3531, 2015.

23. Schmeel LC, Schmeel FC, Coch C and Schmidt-Wolf IG: Cytokine-induced killer (CIK) cells in cancer immunotherapy: Report of the international registry on CIK cells (IRCC). J Cancer Res Clin Oncol 141: 839-849, 2015.

24. Mao Q, Li L, Zhang C, Sun Y, Liu S and Cui S: Clinical effects of immunotherapy of DC-CIK combined with chemotherapy in treating patients with metastatic breast cancer. Pak J Pharm Sci 28 (Suppl 3): S1055-S1058, 2015.

25. Wang $S$ and Wang Z: Efficacy and safety of dendritic cells co-cultured with cytokine-induced killer cells immunotherapy for non-small-cell lung cancer. Int Immunopharmacol 28: 22-28, 2015. 